\title{
CONSTITUCIÓN DEL PLURALISMO Y MÉTODO JURÍDICO ${ }^{1}$
}

\author{
MIGUEL AZPITARTE SÁNCHEZ \\ Profesor Titular de Derecho Constitucional \\ Universidad de Granada
}

\author{
SUMARIO \\ I. Normativismo y función política de la \\ Constitución \\ II. La Constitución del 78 como Constitución \\ del pluralismo \\ III. Consecuencias en el estudio del Derecho \\ constitucional a partir de una racionali- \\ dad basada en el pluralismo
}

\section{NORMATIVISMO Y FUNCIÓN POLÍTICA DE LA CONSTITUCIÓN}

Tras la aprobación de la Constitución de 1978, la naturaleza normativa de sus disposiciones ha sido el dato utilizado de manera central para armar el concepto de Constitución. Se destaca comúnmente que la Constitución es la norma jurídica suprema, dotada de rigidez y garantizada jurisdiccionalmente ${ }^{2}$. Esta

1 El presente trabajo se presentó como comunicación a las Jornadas sobre Orientación y Método del Derecho Constitucional organizadas por la revista Teoría y Realidad Constitucional el 16 de noviembre de 2007

2 Sin duda, el origen de la importancia del concepto normativo de Constitución radica en el influyente libro de E. GARCÍA DE ENTERRÍA: La Constitución como norma y el Tribunal Constitucional, Civitas, $4^{\mathrm{a}}$ ed., Madrid, 2006 (primera edición de 1981). Pero me atrevería a decir, que no menos relevante pudo ser la exposición en contexto histórico del concepto de Constitución normativa realizado por M. García Pelayo: Derecho Constitucional comparado, Alianza, Madrid, 1984, págs. 34 y ss.; y, sobre todo, las Lecciones de derecho constitucional, Ariel, $1^{\text {a }}$ ed. de 1987, de I. De OTTO, que distinguieron con su brillante sencillez el concepto político y jurídico de Constitución, pág. 11 y sigs. Si reconocemos una función decantadora a los manuales de la disciplina, basta una ojeada de los más relevantes para constatar que el carácter normativo de la Constitución es un dato indiscutido. A modo de ejemplo, F. Balaguer Callejón y otros: Manual de Derecho Constitucional, 
perspectiva es imprescindible si se quiere abordar el estudio jurídico del poder. Pero no es suficiente. Desde los albores del constitucionalismo se comprendió que la Constitución nacía con una utilidad instrumental clara - constituir una comunidad política, dar forma a la libertad política ${ }^{3}$ - y precisamente a ese fin era ancilar la estructura normativa. En definitiva, forma y finalidad son las divisas que distinguen al derecho constitucional de otras reglas relativas a la organización del poder ${ }^{4}$.

El argumento principal de este trabajo consiste en afirmar que la función política acaba convirtiéndose en el elemento clave del concepto de Constitución, pues logra dar al texto constitucional un significado contemporáneo. En efecto, cuando la Constitución se reivindica como norma jurídica, se destaca simplemente su pretensión de vincular las conductas de sus destinatarios a lo largo del tiempo ${ }^{5}$. Esa normatividad temporal, esa duración, sólo se alcanza a

Vol. I, Tecnos, $2^{a}$ ed., Madrid, 2007, pág. 109 y ss. P. CRuZ Villalón, <<La Constitución como norma jurídica >>, Base de conocimiento jurídico Iustel, visitada en octubre 2007. L. LóPEz GuerRa y otros: Derecho Constitucional, Vol. I, $5^{\text {a }}$ ed., Valencia, 2002, pág. 40 y ss. No obstante, ya en los manuales se perciben distintos acentos en el concepto normativo de Constitución: "Esa naturaleza normativa implica, ante todo, su condición de fuente del Derecho: es el soporte de las normas constitucionales que se incorporan al ordenamiento" (F. BALAguer, pág. 109). En un sentido similar, destacando la función de fuente: "De ahí que la cuestión de la Constitución como norma jurídica sea, en definitiva la de la Constitución incorporada al ordenamiento jurídico. Y en la medida en que ese ordenamiento se articula en fuentes del Derecho, de las que se quiere hacer a la Constitución, con todas las matizaciones, una más, el tema de esta lección es en buena medida, por más que no exclusivamente, el de la Constitución como fuente del derecho." (P. CRUZ Villalón). Y subrayando su aplicación judicial: "Afirmar que la Constitución tiene naturaleza normativa, que es, en suma, una norma jurídica, no significa otra cosa que considerarla una norma susceptible de aplicación por parte de los poderes públicos encargados de la aplicación del derecho y, señaladamente, por parte de los tribunales", (López Guerra, pág. 41). Es interesante indicar que otros significativos manuales, sin poner en duda la normatividad de la Constitución, prefieren comenzar el estudio del derecho constitucional por uno de sus objetos, el Estado. Así por ejemplo, J. Pérez Royo: Curso de Derecho Constitucional, $10^{\mathrm{a}}$ ed., Marcial Pons, Madrid, 2005, que analiza en paralelo la dimensión ordinamental y estatal del derecho constitucional (lección primera y segunda). Pero sobre todo, O. ALZAGA y otros: Derecho Político Español, Vol. I, que comienza específicamente con tres lecciones dedicadas a la teoría del estado.

3 Por todos, H. Arendt: On Revolution, Penguin, London, 1990 (primera edición 1963), pág. 141 y ss.

4 Es verdad que junto al poder siempre encontramos reglas, cuando menos la regla que señala quién ostenta el poder (aquí, el término regla indica en sentido estricto una regularidad). Sin embargo, no todas esas reglas pueden ser calificadas como derecho constitucional. Es necesaria una distinción si no queremos que cualquier manifestación ordenada del poder se confunda con el derecho constitucional, haciendo así inoperante la diversa denominación de un mismo fenómeno e insustancial la separación científica entre el derecho constitucional y la teoría política. El hecho intelectual por el cual sólo ciertas reglas merecen la denominación de "derecho constitucional" indica ya la disociación objetiva entre el derecho constitucional y el poder. Es precisamente esa frontera la que explica el lugar que ocupa el derecho constitucional en el problema de la legitimidad del poder.

5 A corto plazo cumple una tarea de descarga, ya que el acuerdo en torno a los conflictos de mayor fricción queda fijado con precisión y se libera a la política ordinaria de la permanente disputa sobre cuestiones de división ideológica. Sobre la función del texto constitucional, D. Grimm: $<<$ Die Zukunft der Verfassung >>, en su recopilación Die Zukunft der Verfassung, Suhrkamp, Frankfurt am Main, 1994, pág. 429 y ss. 
través del texto, que gana una importancia crucial en el constitucionalismo contemporáneo. La naturaleza escrita de la norma constitucional permite trazar una distinción entre la Constitución y la generación concreta que la elaboró, de modo que el sentido de la Constitución se hace independiente de las voluntades subjetivas que la forjaron. Así las cosas, desde la aprobación de la Constitución su aplicación es actualización para un momento y una controversia concreta $^{6}$. El tránsito de la disposición escrita a la norma aplicada consigue que el pacto constituyente se haga presente, afín a cada momento histórico, sosteniendo la durabilidad de la Constitución y su vigencia sobre las generaciones vivas.

Ocurre, sin embargo, que el texto constitucional se revela limitado por su propia condición histórica y por su pretensión de vigencia indefinida ${ }^{7}$. Fruto de un acuerdo determinado, sus disposiciones contendrán principios, estudiadas ambigüedades, silencios conscientes y, sobre todo, ignorancia ante los retos venideros. Así las cosas, la vocación de trascender el momento histórico de creación para regular con continuidad la organización política de una comunidad, explica las características del texto. Ante esos rasgos semánticos, se hace imperiosa una racionalidad política que le dé sentido contemporáneo al texto, concretando la flexibilidad de los principios, salvando las ambigüedades, llenando los silencios, respondiendo a los nuevos retos, en definitiva, dotándolo de un contexto sistemático que contribuye a actualizar la normatividad de la Constitución en 2007.

Este argumento central - la lectura de la Constitución desde una racionalidad política - sostiene la premisa inicial: la relegación que ha padecido la función política en la construcción del concepto de Constitución, a favor de una comprensión esencialmente normativista. Durante mucho tiempo ha bastado con afirmar que el concepto de Constitución se resume en su cualidad de norma jurídica ${ }^{8}$. Bajo este escenario, la cuestión a resolver consistiría en aclarar cuáles han sido los motivos que han provocado esta reducción. Seguramente, una primera causa tendría que ver con la cercanía del momento constituyente, que siempre alzaprima la función transformadora de la norma constitucional. La

6 Debemos a GADAMER la perspicaz apreciación que nos explica cómo la comprensión de un texto nunca es un mero entendimiento histórico, sino que necesariamente conlleva una intención aplicativa, H-G. Gadamer: Verdad y Método, 9ª Ed., Sígueme, Salamanca, 2001, pág. 378 y ss.

7 La vigencia indeterminada de la Constitución se conecta con sus propios rasgos formales supremacía y rigidez-, y con sus rasgos materiales - normas abstractas que permiten su adaptación en el tiempo (Ferreres), normas que incorporan valores de realización inagotable (De Cabo)-, cfr. C. DE CABO: La reforma constitucional, Trotta, Madrid, 2003, pág. 22; V. FERRERES COMELla: <<Una defensa de la rigidez constitucional>>, Doxa, 2000, pág. 33.

8 Lo cual no evitaba, que en la praxis, el texto se leyera con una u otra comprensión material. Esto se refleja en las interesantes opiniones de C. DE CABO, A. Garrorena y M. Aragón a la segunda pregunta formulada en la Encuesta de la Revista Teoría y Realidad Constitucional, núm. 1, 1998, «En todo caso, subsisten diferencias en los modos de trabajar de los estudiosos que se ocupan de la Constitución. ¿Cómo podrían resumirse las orientaciones metodológicas fundamentales en el actual Derecho Político español?" Los tres autores exponen diversas formas de concebir el derecho constitucional, sin poner en tela de juicio la propia normatividad de la Constitución. 
Constitución organiza el tránsito de régimen y esto se logra con su plena eficacia normativa; si no transforma la realidad fracasa en su efectividad. Además, en este tiempo, y aquí estaría una segunda razón, resplandecía todavía el consenso labrado en torno a la Constitución. Tal consenso significaba simplemente que el disenso político podría centrarse sobre la intensidad y la velocidad de la transformación de la realidad político-jurídica, pero nunca sobre las bases constitucionales que armaban esa transformación, de manera que se oscurecía la inevitable dimensión política de las normas que organizaban esas bases. Finalmente, la función transformadora y el consenso político impactaron sobre el espacio académico. Se asentó un paradigma científico indiscutido - la Constitución como norma jurídica-, que permitió profundizar en el estudio dogmático y técnico de sus disposiciones, creando toda una variedad de instrumentos que venían a limpiar y potenciar la aplicación (la normatividad) de la Constitución?

Con todo, era cuestión de tiempo y prueba de normalidad que el debate sobre la racionalidad política de la Constitución volviera a emerger. En una democracia constitucional pujante, la discusión sobre la función de la Constitución no se agota (porque nunca termina la propuesta sobre el fin de la organización política común). Es más, refleja la propia confianza en la capacidad ordenadora de la Constitución. Actualmente, el origen de este debate está en la praxis constitucional y penetra paulatinamente en la academia. La discusión ha afectado a dos de la bases constitucionales, el proceso de integración europea y el Estado autonómico ${ }^{10}$. Para el primer caso, la frustrada ratificación de la Constitución europea abrió una conversación sobre lo que ha de ser una Constitución y sobre la propia función de nuestra Constitución respecto al derecho europeo. Igualmente, las reformas estatutarias han planteado la función de la Constitución en relación con los poderes estatuyentes y, sobre todo, han formulado al-

9 La normatividad de la Constitución opera en un doble sentido. Agrupa a una corriente que subraya este elemento en la construcción del concepto de Constitución, pero también sirve para reunir a otros estudiosos cuyo punto en común es destacar las insuficiencias de un concepto de ese tipo. En este segundo sentido, es necesario destacar aquellos autores que aspiran a trabajar con el derecho constitucional tomando como pieza clave al Estado social. Se trata de una corriente con una gran potencia crítica que quiere destacar las contradicciones que provoca el Estado social en la comprensión del derecho constitucional y la democracia. Así, pienso que un ensayo medular para comprender esta perspectiva es C. DE CABO: <<Democracia y derecho en la crisis del Estado social $>>$, Sistema, núm. 118-119. Concretamente para situar la crisis de la normatividad de la Constitución es muy interesante el trabajo de G. MAEstro: <<Globalización y Constitución débil >>, Teoría y Realidad Constitucional, núm. 7, 2001.

10 Alguna reflexión merecen las otras dos bases constitucionales, el Estado social y el principio democrático. En el primer caso la discusión en la praxis política ha sido intensa (pensemos en el proceso privatizador o la intensa regulación de los ciclos presupuestarios), pero se ha desarrollado fuera del debate constitucional y se ha resuelto por vía legislativa. En el caso del principio democrático, parece complicado esperar una discusión de naturaleza constitucional sobre la estructura de la democracia de partidos. No obstante, el surgimiento de nuevos partidos o algunas propuestas sobre la necesidad de reformar la Loreg sea para facilitar el gobierno del partido más votado o para reducir la presencia en las Cortes de partidos sin dimensión estatal, presentan algunas líneas de reflexión que podrían desembocar en un debate sobre la base democrática de la Constitución. 
ternativas en torno a los contenidos exclusivos de una Constitución y a la supuesta "apariencia de Constitución" de los Estatutos. Lo que importa ahora es tan sólo resaltar cómo una u otra posición técnica, tanto en el proceso de integración como en las reformas estatutarias, han puesto de manifiesto diversos modos de comprender — de leer- la Constitución. El sentido político de la Constitución ya no se escamotea, sino que ocupa el centro del debate ${ }^{11}$.

La condición normativa de las disposiciones constitucionales es un a priori fuera de toda duda. El problema ahora consiste en concretar el sentido de una disposición abierta a diversas posibilidades jurídicas. Y en esa tarea, la racionalidad política, expresa o no, carga de normatividad el texto. Y es inevitable que esa racionalidad fije además el método jurídico, el camino que arma y explica las consecuencias de una o varias disposiciones jurídicas. Racionalidad político-constitucional, tránsito de la disposición a la norma y método operan como una triada inseparable.

Mi intención a lo largo de estas páginas es profundizar en las consecuencias metodológicas que conlleva la comprensión de la Constitución como una norma jurídica que habilita y ordena el pluralismo en sus diversas manifestaciones. Es evidente, por tanto, que tomo partido a favor de una lectura concreta de la Constitución. Para evitar malentendidos, volveré brevemente sobre las características del pluralismo y cómo se manifiesta en el texto normativo. Esta parte tendrá mucho de revisión, pero será necesaria para trabajar con un contexto adecuado a la hora de proponer criterios metodológicos. En definitiva, sólo desde la función podemos llegar al método.

\section{LA CONSTITUCIÓN DEL 78 COMO CONSTITUCIÓN DEL PLURALISMO}

\section{Breve revisión conceptual del pluralismo politico}

En una dimensión prescriptiva, el pluralismo político se ancla teóricamente sobre tres elementos correlativos. El primero, de corte epistemológico, concibe la verdad como un proyecto eternamente irresoluto; al ser humano no le es disponible la verdad en su totalidad. Esta inestabilidad, transferida a las ambiciones de verdad política, lleva sin solución de continuidad a la libertad, segundo elemento del pluralismo. Todos han de ser libres, bien para elegir su verdad personal entre los modelos existentes, bien para proponer al foro otros modelos $^{12}$.

11 Es importante subrayar que el debate sobre el concepto de Constitución en la praxis política ha nacido en el extrarradio del proceso político que expresamente ordena la Constitución. No son las Cortes ni los partidos mayoritarios de ámbito nacional los que proponen nuevos modos de entender la Constitución.

12 Sobre la conexión entre epistemología y libertad política, cfr. H. HuBA: $<<$ Zur Verfassung der Theorie des Pluralismus >>, Der Staat, núm. 33, 1994, pág. 581; y, H.F. ZächER. <<Pluralität der Gesellschaft als Rechtspolitische Aufgabe>>, Der Staat, núm. 2, 1970, pág. 161. En definitiva, el plu- 
$\mathrm{Al}$ aceptar como elemento clave de la racionalidad política la ausencia de una verdad definitiva, que a la sazón exige la generalización de la libertad, es posible, entonces, alcanzar una primera definición del pluralismo político: en la sociedad concurren y se manifiestan diversas posiciones ideológicas, económicas, culturales, religiosas, etc., fruto de la autonomía de cada individuo. Sin embargo, una definición más apurada, que entra ya en el plano descriptivo, presenta el pluralismo como la concurrencia de grupos, colectivos que reúnen a un número de ciudadanos en torno a singulares intereses o posiciones. La realidad del pluralismo político no es una pura atomización, sino más bien una complejidad que se ordena y simplifica en primera instancia gracias a la capacidad asociativa de los individuos ${ }^{13}$ (esencialmente mediante los partidos políticos). Pero la definición del pluralismo político no concluye al indicar la confluencia de distintos grupos. Necesita para ser ajustada subrayar que los diversos grupos sociales deben tener un acceso al proceso político, económico, cultural, etc., libre y proporcional a su importancia ${ }^{14}$. Sin la inserción del pluralismo en la dinámica estatal, carece de sentido hablar de libertad política, que constituye así el tercer elemento del pluralismo.

\section{Elementos que justifican una lectura pluralista del texto constitucional}

El pluralismo se hace patente en el propio contenido de la Constitución ${ }^{15}$. Los derechos fundamentales abren la expresión de la diferencia, sea para garantizar la presencia de la minoría política en la dinámica de poder, o para asegurar la existencia de la minoría distinguida por rasgos invariables y sin pre-

ralismo como teoría política es deudora en gran medida del racionalismo crítico popperiano, sobre esta conexión, P. HÄBERLE: <<Verfassungsinterpretation als öffentlicher Prozess -ein Pluralismuskonzept->>, en su libro Verfassungslebre als Kulturwissenschaft, $2^{\mathrm{a}}$ ed., Duncker\&Humblot, Berlin, 1998, pág. 143.

13 La concurrencia de grupos pasó a ser el frente político-teórico de la nueva sociedad tecnológica de masas, en un intento de sustituir como referente al concepto de la "sociedad de clases", cfr. K. Lowenstein en su Teoría de la Constitución, trad. de Gallego Anabitarte, 2a ed., Ariel, 1976, pág. 427; y, C.B. MacPherson: La democracia liberal y su época, trad. F. Santos, Alianza, 1982, Madrid, pág. 89.

14 En su expresión más optimista, la teoría democrática consideraba que esa confluencia de grupos alcanzaría un equilibrio armónico que permitiría el gobierno con respeto a la minoría. En mi opinión, siguiendo a SCHEUNER y LowENSTEIN es secundario el producto espontáneo de la concurrencia grupal. Lo importante es su existencia y que ese pluralismo se filtre en las instituciones estatales. Cfr. en este sentido U. Scheuner: <<Konses und Pluralismus als Verfassungsrechtliches Problem $>>$, en su recopilación Staatstheorie und Staatsrecht, dir. Listl/Rüfner, Ducnker\&Humblot, pág. 146; y, K. LOWENSTEIN en su Teoría de la Constitución, trad. de Gallego Anabitarte, $2^{\mathrm{a}}$ ed., Ariel, 1976, pág. 432 y ss.

15 Lo que HäBERle ha llamado "el pluralismo constitucionalizado" (der verfasste Pluralismus). Estas páginas son en gran medida deudoras del citado profesor, cuya obra culmen Verfassungslehre als Kulturwissenschaft es un esfuerzo por revisar las categorías clásicas del derecho constitucional -el poder constituyente, la reforma de la constitución, el sistema de fuentes, la jurisdicción constitucional, la interpretación, etc.— desde una teoría pluralista. 
tensión de conformar el discurso político. El sistema electoral transporta al Parlamento las corrientes sociales de mayor relevancia. La presencia del pluralismo social en el Parlamento, su funcionamiento definido por la discusión pública y su competencia para otorgar o negar la confianza al Gobierno, sitúan a las Cortes en el centro de un sistema político que se define por la división entre mayoría de gobierno y oposición, y la posibilidad de que ésta devenga en mayoría a lo largo de los sucesivos periodos electorales. La organización territorial determinada por el Estado autonómico se sustenta sobre diferentes criterios de legitimidad, pero, indudablemente, una de sus razones principales es la ordenación del pluralismo nacional y/o territorial. Finalmente, la propia estructura normativa de la Constitución refleja la incidencia del pluralismo. Si el momento constituyente se entiende como la puesta en común de las distintas fuerzas políticas, no ha de sorprender la estructura de las disposiciones constitucionales. Pretenden excluir posibilidades y dejar abierto un margen amplio en el que actuarán las mayorías contingentes. La configuración normativa de la Constitución permite la solución de nuevas realidades o el cambio de orientación en viejos problemas, en definitiva, ordena el pluralismo en el tiempo ${ }^{16}$.

\section{CONSECUENCIAS EN EL ESTUDIO DEL DERECHO CONSTITUCIONAL A PARTIR DE UNA RACIONALIDAD BASADA EN EL PLURALISMO}

\section{Apertura del objeto}

En la lectura pluralista de la Constitución se presupone que la política (la discusión sobre las alternativas en la toma de decisiones), es el elemento fundacional de la Constitución y del Estado ${ }^{17}$. La Constitución plasma el

16 En mi opinión sigue siendo K. Hesse la autoridad que con mayor precisión ha explicado la conexión entre la estructura normativa de la Constitución y su función como "rechtliche Grundordnung des Gemeinwesens". La alternancia entre precisión y apertura textual es un juego para equilibrar dinámica y estática en la ordenación de la vida estatal y social, cfr. K. Hesse: Grundzüge des Verfassungsrechts der Bundesrepublik Deutschland, 20ª ed., C.F. Müller, Heidelberg, 1995, pág. 11 y ss.

17 La discusión, la persuasión y el compromiso como elementos distintivos de la política frente a la corriente que reduce la política a la decisión y que inevitablemente se sustenta sobre el dominio en forma de monopolio de la violencia, cfr. E. HAuptMann: <<A local history of "the political» $>$, Political Theory, Vol. 32, 34-60, 2004. No me resisto a citar textualmente las lapidarias palabras de ZaGREBELSKY: "Para las doctrinas del Estado de derecho, el Estado como organización jurídica producía actos jurídicos. Para la nueva concepción, la política produce el Estado, el cual produce derecho politizado", palabras entresacadas de su epílogo a C. MORTATI. La Constitución en sentido material, trad. A. Bergarache Gros, CEPC, Madrid, 2000, pág. 249; igualmente HuBA afirma "Die Pluralismustheorie trifft den Nerv der Politik... Die Politik erhält den Auftrag, die Gesellschaft zu integrieren...", H. HubA: <<Zur Verfassung der Theorie des Pluralismus>>, Der Staat, núm. 33, 1994, pág. 591. Y es verdad que desde esta posición "la Constitución es una norma antropológicamente optimista, que presume la inocencia del hombre frente al poder... Para ello necesita inspirarse en 
consenso básico de una comunidad plural (sobre quién decide, con qué límites y para qué fines); y el Estado es el resultado institucional de ese consenso. Pero la Constitución no agota la política, ciñe los puntos de acuerdo y establece un marco susceptible de variados desarrollos. En consecuencia, el Estado no produce meramente derecho, sino que incorpora un derecho politizado que colma la estructura constitucional en atención a las mayorías y minorías contingentes ${ }^{18}$. Así, junto a la Constitución, la política-constitucional da forma completa a nuestro régimen constitucional articulando el cambio en el tiempo.

La distinción entre Constitución y política constitucional implica distintas consecuencias. Evidentemente supone una ampliación (o clarificación) del objeto de estudio. La acción legislativa (estatal y autonómica) desarrollando las posibilidades constitucionales, la intervención del Tribunal Constitucional actualizando el significado de las disposiciones constitucionales y la incidencia de la potestad pública de la Unión en las bases constitucionales, se hacen imprescindibles en el estudio de la organización jurídica del poder; e incluso presentan problemas propios para cada uno de esos ámbitos ${ }^{19}$. Pero ahora me interesa destacar la repercusión de la distinción entre Constitución y política constitucional sobre el modo de estudiar el derecho constitucional, en definitiva, sobre la tarea del constitucionalista.

El derecho constitucional es una disciplina jurídica (y, por tanto, ha de ser critica)

Afirmar que el derecho constitucional es una disciplina jurídica, señala la naturaleza de su objeto de estudio, las normas jurídicas ${ }^{20}$. Pero al mismo tiempo indica también la tarea propia del constitucionalista: contribuir a identificar y enunciar las normas a partir de un texto incorporado por una fuente del de-

una serie de obligados mitos fundacionales", F. CAAMAÑO: <<iQué es una Constitución?>>, Rev. Española de Derecho Constitucional, núm. 58, pág. 356.

18 Véase el acento que vuelve a marcar R.C. POST: <<Foreword: fashioning the legal constitution: cutlure, courts, and law $>>$, Harward Law Review, Vol. 117:4 2003, en especial pág. 8 y ss. Y, sobre todo, B. AcKerman: <<The living Constitution>>, Harvard Law Review, Vol. 120:7 2007.

19 Esta ampliación del objeto nos debe llevar a superar una visión exclusivamente judicialista del derecho constitucional y a elaborar métodos particulares en el estudio de la legislación, la jurisprudencia y el derecho europeo. Por ejemplo, para entender el concepto de derecho fundamental no basta con la jurisprudencia constitucional, se hace también precisa la legislación e incluso la propia concepción del derecho por parte del titular manifestada a través de su ejercicio.

20 Se trata, eso sí, de una norma peculiar, basta con recordar las anotaciones del primer epígrafe y, en todo caso, dos estudios clásicos, A. NiETO: <<Las peculiaridades de la norma constitucional >>, Rev. Administración Pública, núm. 100-102, 1983; sin olvidar el trabajo fundamental de A. HOLLERBCH: <<Auflösung der Rechtsstaatlichen Verfassung?>>, en Verfassung, dir. M. Friedrich, ed. Wissenschaftliche Buchgesellschaft, Darmstadt, 1978. 
recho ${ }^{21}$. El derecho constitucional, por tanto, comparte con el resto de disciplinas jurídicas la esencia de su objeto y función ${ }^{22}$.

Sin embargo, se ha de conjurar de modo inmediato el riesgo de que el derecho constitucional se convierta en una disciplina meramente descriptiva de la política constitucional ${ }^{23}$. El constitucionalista no puede limitarse a conocer el mapa normativo en el que se desenvuelve: lo real no es constitucional; es insuficiente dar registro del modo concreto y efectivo en el que la Constitución es aplicada y desarrollada. El estudio del derecho constitucional debe ser también prescriptivo. El conocimiento de la realidad normativa es el punto de partida indispensable que permite realizar una labor crítica, encaminada a señalar aquellos desarrollos que debilitan la supremacía y normatividad de la Constitución ${ }^{24}$. El constitucionalista debe tomar siempre a la Constitución como patrón en el estudio de la realidad constitucional. En estas circunstancias, el constitucionalista de perfil académico, esto es, el profesor, se convierte con título propio en un actor más dentro de la sociedad abierta de los intérpretes constitucionales ${ }^{25}$.

Pero a su vez, esa posición primordial de la Constitución en la labor del constitucionalista no ha de significar la petrificación de la Constitución como paradigma inexpugnable. La posición crítica del constitucionalista se debe extender al propio texto constitucional. La Constitución tiene una función precisa, cuya hipotética crisis ha de ser diagnosticada por el constitucionalista. Este dato, además, es el rasgo que separa al académico del resto de operadores jurídicos en otras posiciones institucionales, por ejemplo un magistrado del Tribunal Constitucional o un funcionario (verbigracia, un letrado de Parlamento). Éstos operadores están sometidos a la Constitución en el desempeño de su función profesional, y su crítica intelectual a la misma sólo surge ya en el ámbito de su esfera privada. Por el contrario, en el caso del académico, el análisis crítico de la Constitución es un elemento propio de su tarea profesional (y pública) ${ }^{26}$.

21 M. Dogliani: Indirizzo Político. Riflessioni su regole e regolarità nel diritto costituzionale, Jovene, Napoli, 1985, pág. 2.

22 No creo, sin embargo, que el debate pueda presentarse como una discusión relativa a la singularidad o uniformidad del método constitucional respecto a otras disciplinas. La afirmación de la peculiaridad del método constitucional o de su plena afinidad con otras disciplinas es una propuesta vacía, pues la pluralidad de métodos es algo compartido por todas las disciplinas. En fin, es posible leer el Código Civil desde distintos ángulos, como es posible comprender la Constitución a partir de perspectivas varias.

23 Señalado ya con certeza por M. Doglian durante los ochenta en su libro Indirizzo Politico. Riflessioni su regole e regolarità nel diritto costituzionale, Napoli, Jovene, 1985, en especial pág. 1-23.

24 Esta idea la refleja el profesor DE CABO al analizar "la necesidad de la reforma" en su libro La Reforma Constituiconal, Trotta, Madrid, 2003, pág. 75 y ss.

25 Debemos al profesor P. HäBERLE la ampliación del círculo de los autorizados a participar en el discurso interpretativo, véase su trabajo $<<$ Zeit und Verfassung $>>$, en Verfassungslebre als Kulturwissenschaft, Duncker\&Humblot, Berlin, en pág. 83 y ss.

26 P. HÄBERLE: <<Demokratische Verfassungstehorie im Lichte des Möglichkeitsdenkes〉>, en Verfassung als öffentliches Prozess, $2^{\mathrm{a}}$ ed., Duncker\&Humblot, Berlin, 1996. 
El derecho constitucional es una disciplina jurídica orientada a la resolución de problemas (es una disciplina pragmática)

La tarea del constitucionalista, identificar y elucidar la norma constitucional, surge sólo a partir de una controversia sobre el sentido de la Constitución. Es decir, el derecho constitucional como disciplina jurídica existe únicamente porque es útil para resolver problemas. Así las cosas, siguiendo a VIEWEGH ${ }^{27}$, se ha de afirmar que el derecho constitucional, al igual que cualquier otra disciplina jurídica, es una actividad pragmática que entra en acción para formular una regla a partir de un texto normativo y frente a una controversia jurídica ${ }^{28}$. El derecho constitucional es una disciplina en contexto.

Esta concepción del derecho constitucional como disciplina pragmática impone unas consecuencias insoslayables sobre el método. En primer lugar, la tarea del derecho constitucional nace para un problema concreto que tiene una latitud histórica y política. Pero si la norma constitucional se formula en un ambiente determinado, carece entonces de todo sentido querer sostener su singularidad científica sobre la separación respecto de otras ciencias sociales. Me atrevo a decir que esas otras ciencias sociales (la historia, la ciencia política, la filosofía, etc.), sin hablar de otras disciplinas jurídicas, no son meros instrumentos auxiliares del constitucionalista, sino que verdaderamente se insertan con plenitud, consciente o inconscientemente, en la formulación de la norma constitucional. La controversia que exige la aplicación de una norma constitucional tiene razones históricas y políticas, cuya explicación incide sobre aquel que aplica la norma o estudia su aplicación.

El hecho de que la disciplina del derecho constitucional deba resolver problemas tiene una segunda consecuencia metodológica que ya ha sido anunciada en el párrafo anterior al destacar la naturaleza subjetiva del proceso interpretativo. Debemos a EHMKE $^{29}$, que trasladó al derecho constitucional las reflexiones generales de la teoría de la interpretación ${ }^{30} \mathrm{y}$ del derecho privado ${ }^{31}$, el esfuerzo por destacar la incidencia de la precomprensión en la interpretación de la Constitución. El constitucionalista se desenvuelve en un contexto que incide sobre su lectura de la Constitución. El constitucionalista se acerca al texto normativo con una precomprensión, y vuelve a ésta desde el texto a modo de círculo permanente. Ahora bien, la disciplina del derecho constitucional no ha de frenarse en tal constatación. Un tratamiento riguroso del derecho constitu-

27 T. Viewegh: Tópica y Jurisprudencia, trad. L. Díez Picazo, Taurus, Madrid, 1964.

28 Cobra así pleno sentido la distinción entre disposición y norma de V. CRISAFULLI: <<Disposizione (e norma)>>, en Enciclopedia dil Diritto, Vol. XIII, 1964.

29 H. Eнмке: <<Prinzipien der Verfassungsinterpretation>>, publicado inicialmente en 1963, cito por su recopilación en la obra del mismo autor Beiträge zur Verfassungstheorie und Verfassungspolitik, comp. Häberle, Athenäum, Königstein, 1981.

30 G. Gadamer: Verdad y método, trad. de A. Agud y R. de Agapito, 9a ed., Sígueme, Salamanca, 2001

31 De nuevo VIEWEGH, siendo también necesaria la referencia a J. ESSER: Grundsatz und Norm in der richterlichen Fortbildung des Privatsrechts, Mohr/Siebeck, Tübingen, 1956. 
cional requiere que el constitucionalista explicite la precomprensión que alimenta su interpretación constitucional. El constitucionalista observa la Constitución creyendo que el texto está insuflado por una razón que le da sistemática y orden ${ }^{32}$. Es esa razón la que debe verbalizar en argumentación jurídica para que la discusión teórica goce de una narrativa racional. En caso contrario, el debate entre constitucionalistas corre el riesgo de ser inconmensurable ${ }^{33}$.

\section{El derecho constitucional es una disciplina dogmática}

Cuando el constitucionalista trabaja con el objeto del derecho constitucional, lo toma como una realidad normativa dotada de un sentido racional que le da coherencia. Piensa el constitucionalista (como cualquier otro jurista) que el conjunto de preceptos constitucionales se reconduce a unos cuantos principios materiales capaces de explicar la unidad del ordenamiento constitucional. Precisamente en esta presunción de sistematicidad radica la propia consideración científica de la tarea que desempeña el constitucionalista: porque la Constitución compone un sistema, es posible establecer los conceptos generales de ese sistema. El derecho constitucional es, por tanto, una disciplina dogmática. Con este adjetivo, de largo arraigo en los estudios jurídicos ${ }^{34}$, quiero indicar que el derecho constitucional, como cualquier otra ciencia o disciplina, tiende a trabajar con categorías abstractas y generales ${ }^{35}$. La disciplina del derecho constitucional se acerca a la pléyade normativa con la intención de reducir su complejidad a la síntesis y generalidad de un concepto, que nos sea útil para enfrentarnos y distinguir otros grupos normativos similares.

El hecho de que la disciplina del derecho constitucional trabaje con conceptos incluye en su tarea una vocación de teoría genera ${ }^{36}$. Esta circunstancia contradice aparentemente la conclusión del epígrafe anterior, en la que se presentaba al derecho constitucional como una disciplina pragmática apegada al problema. Ciertamente se trata de dos paradigmas concurrentes, aunque creo que no necesariamente excluyentes. Ya señalé también en el epígrafe anterior que el constitucionalista ha de trabajar con un concepto racional si quiere crear un discurso narrativo comprensible para el resto de intérpretes. Por de-

32 Cfr. C-W. CANARIS: Systemdenken und Systembegriff in der Jurisprudenz, Duncker\&Humblot, Berlin, 1969, en especial, pág. 40 y ss.

33 Hago mías las reflexiones genéricas sobre la inconmensurabilidad del debate moral que ofrece A. Macintrre: Tras la virtud, $2^{\mathrm{a}}$ ed., trad. de A. Valcárcel, Crítica, Barcelona. 2004.

34 Basta con repasar las siempre importantes apreciaciones de K. LARENZ: Methodenlehre der Rechtswissenschaft, 6a ed., Springer, Berlin, 1991, pág. 250 y ss.

35 Creo extensibles a cualquier rama jurídica las reflexiones que incorpora E. ScHMIDT-AssMANN: Das allgemeine Verwaltungsrecht als Ordnungsidee, Springer, 1998, en especial pág. 5.

36 No extraña la contundente reivindicación que de la teoría general ha realizado el profesor J.J. Gomes Canotilho, véase su libro Direito Costituzionale e Teoria da Constituiçao, $3^{\text {a }}$ ed., Almedian, Coimbra, 1999 y la muy interesante entrevista que le realizó el profesor E. GARCÍA: $<<$ El derecho constitucional comparado como un compromiso permanentemente renovado $>>$, Anuario de Derecho Constitucional y Parlamentario, núm. 10, 1998. 
cirlo de otro modo, el constitucionalista necesita una teoría constitucional, que a su vez se formula y modifica en atención a los problemas que suscita la realidad aplicativa. El derecho constitucional ha de ser, en un difícil equilibrio, pragmático y dogmático al mismo tiempo.

En todo caso, la vocación de teoría general ínsita al derecho constitucional abre la labor del constitucionalista en un triple sentido. Primero, conecta al constitucionalista con el devenir histórico de su disciplina. Los conceptos tienen una carga histórica que se proyecta sobre su comprensión contemporánea. El constitucionalista enriquece el planteamiento de su tarea si conoce la formulación y evolución de los conceptos constitucionales. E incluso, en ocasiones, ese conocimiento es insoslayable porque algunos de esos conceptos se han trasladado al propio texto normativo. En segundo lugar, el ejercicio de una teoría general permite el diálogo entre constitucionalistas que trabajan en escenarios jurídicos distintos. En el caso español, esta precisión es innegable, pues nuestro derecho constitucional se construye en gran medida incorporando categorías forjadas en Alemania, Italia o Estados Unidos. La dogmática comparada (y por ende el derecho comparado) son hoy instrumentos fundamentales en el estudio del derecho constitucional ${ }^{37}$. Finalmente, y quizá más importante, la elaboración de una teoría general del derecho constitucional permite afrontar los retos del futuro. En este sentido es ejemplar el esfuerzo que se ha realizado y se está realizando ante el proceso de integración europea. La fuerza expansiva del derecho comunitario ha obligado a los constitucionalista a tomarlo en serio como derecho materialmente constitucional. Y en estas circunstancias, el constitucionalista se ha visto y se ve en la necesidad de replantear la raíz de las categorías tradicionales para elucidar su utilidad ante el nuevo fenómeno jurídico que supone la integración ${ }^{38}$.

37 Sobre la importancia del derecho comparado, incluso catalogado como quinto método interpretativo véase P. HÄBERLE: <<Kulturelle Verfassungsvergleichung - Verfassungsvergleichung als "fünfte" Auslegunsmethode >>, en su recopilación Verfassungslehre als Kulturwissenschaft, $2^{\mathrm{a}}$ ed., Duncker\&Humblot, Berlin, 1998, pág. 312 y ss.

38 Sobre esta impulso metodológico cfr. E.U. PETERSMAnN: <<Proposals for a new Constitution for the European Union: bulding-blocks for a constitutional theory and constitutional law $>>$, CMLR 32: 1123-1175, 1995; I. PERNICE: <<Multilevel constitucionalism and the Treaty of Ámsterdam: european constitutionalism-making revisited $>>$; A. von BOGDANDY: $<<$ Notas sobre la ciencia del derecho europeo $>>$, Teoría y Realidad Constitucióna, núm. 5, 2000; N. WALKER: <<The Idea of Constitutional Pluralism>>, MLR, Vol. 65, 2002. 
ABSTRACT.- The paper underlines the predominance of the normative element in the construction of the constitutional concept. This approach is very important but in the actual circumstances it must be completed by the understanding of the political function of the Constitution. The author proposes to read the Constitutional text trough the political idea of pluralism which brings some methodological consequences. Constitutional law must work with a normative element but as well with a pragmatic and dogmatic element. These three elements permit to find some answers in the openness of the political reality ruled by the Constitution. 